\title{
Mechanical Behavior of Triaxial Geogrid Used for Reinforced Soil Structures
}

\author{
Jun Zhang $\mathbb{D}^{1,2,3}$ Wen-Zhao Cao $\mathbb{D}^{3,4}$ and Yan-Jun Zhou $\mathbb{D}^{3,5}$ \\ ${ }^{1}$ College of Transportation Engineering, Tongii University, Shanghai 201804, China \\ ${ }^{2}$ Key Laboratory of Highway Construction and Maintenance Technology in Loess Region, \\ Shanxi Transportation Technology Research \& Development Co., Ltd., Taiyuan 030032, China \\ ${ }^{3}$ Institute of Geotechnical and Underground Engineering, Huazhong University of Science \& Technology, Wuhan 430074, China \\ ${ }^{4}$ Central Research Institute of Building and Construction (Shenzhen) Co., Ltd., MCC Group, Shenzhen 518055, China \\ ${ }^{5}$ Fujian Institute of Geotechnical Engineering Investigation and Surveying Co., Ltd., Fuzhou 350000, China
}

Correspondence should be addressed to Jun Zhang; zj_sxjt@hotmail.com

Received 8 January 2021; Revised 29 January 2021; Accepted 10 February 2021; Published 19 February 2021

Academic Editor: Chong Xu

Copyright (c) 2021 Jun Zhang et al. This is an open access article distributed under the Creative Commons Attribution License, which permits unrestricted use, distribution, and reproduction in any medium, provided the original work is properly cited.

Geosynthetics-reinforced soil (GRS) structures have been widely used for the prevention of geological hazards. As a recently introduced product, the triaxial geogrid has been confirmed to provide improved performance due to the more stable grid structure. This paper presents an evaluation of the mechanical behavior based on a series of laboratory tests. The unconfined tensile strength of biaxial geogrid and triaxial geogrid in different loading directions relative to the orientation of ribs was investigated. Then, more than 8 pullout tests were conducted on the triaxial geogrid specimens embedded in the compacted sand. The internal displacements along the geogrid length were monitored. The results show that the triaxial geogrid has been shown to provide nearly uniform tensile strength in all loading directions as compared with the biaxial geogrid. The triaxial geogrid deformation is mainly characterized by rib bending and nodal distortion along with an inward squeeze perpendicular to the pullout direction. The interface friction between the soil and the geogrid develops in a progressive mode, and an elasto-plasticsoftening characteristic is detected experimentally due to the extensibility of geogrid.

\section{Introduction}

Geosynthetic-reinforced soil (GRS) structures are widely constructed on account of their economic advantages, successful performance, and environmentally friendly. For the prevention of geological hazards, such as landslides induced by the rainfall, as one kind of effective retaining structure, GRS structures have been widely used to repair the excavated mountains in recent years. However, it is worth noting that the performance of GRS structures is largely governed by the interface behavior between the geosynthetics and the backfill soil $[1,2]$. The interaction developed along the soil-geosynthetic interface is very complex due to the effect of the physical and mechanical properties of the soil and geosynthetics, as well as the loading conditions [3]. For extensible reinforcements, tensile deformation, along with the load transfer from unstable portions to the stable zones, will increase the complexity of the analysis of interaction mechanism [1].

Uniaxial and biaxial geogrids are two common types of geogrids which have been used successfully worldwide for soil reinforcement, including reinforced slopes, retaining walls, and embankments using uniaxial geogrids and pavements using biaxial geogrids. Significantly improved performance of GRS structures was investigated and confirmed through laboratory tests and field applications [4]. However, the uniaxial geogrid is only suitable for the GRS structures of which the unanticipated failure is only possible to occur in the predictable direction. As for biaxial geogrids, if subjected to tension in different direction apart from the longitudinal and transverse direction, especially in the $45^{\circ}$ loading direction, large reduction of tensile strength should also be taken into account. Considering the limitation of uniaxial and biaxial geogrids, a recently introduced geogrid 
product with triangular apertures (i.e., triaxial geogrid) has been manufactured to settle this deficiency, as shown in Figure 1.

The geometrical characteristic of triaxial geogrid is obviously different and more complicated compared with uniaxial and biaxial geogrids. The triaxial geogrid has also been confirmed experimentally and numerically to provide improved performance over the biaxial geogrid in some aspects due to the more stable grid structure which can provide nearly uniform properties in all directions [5-9]. The tensile strength and stiffness of the triaxial geogrid were relatively uniform at all the loading directions even though those at the $45^{\circ}$ loading were slightly lower [5]. More uniform stress and strain distributions among the ribs were also obtained. Meanwhile, when used to improve soft subgrade and reinforce weak base courses, triaxial geogrids had significantly reduced the maximum vertical stress on the subgrade and resulted in a more uniform stress distribution [6]. As the finite element method and finite difference method cannot provide full insight into the complex interaction between the granular soil or ballast and the triaxial geogrid, the discrete element method had also been used to provide much needed micromechanical investigation and more detailed working mechanism has been uncovered [7]. A series of laboratory pullout tests were conducted on triaxial geogrid specimens considering the effect of two kinds of pullout directions $[8,9]$. The interaction of triaxial geogrid could be better enhanced with the increase of vertical stress compared with that of biaxial geogrid.

Nevertheless, due to the relatively recent introduction of this product, the interface behavior between the triaxial geogrid and compacted soil has not been well tested and evaluated, and most of the existing research studies are also only carried out by numerical simulation $[5,7]$. Pullout tests are commonly employed to address the problems associated with soil-geosynthetic interaction, to characterize the stress transfer mechanisms, and to obtain the interface strength parameters which are of utmost importance for the design and construction of reinforced soil structures [10-14].

This paper presents an evaluation of the mechanical behavior based on the results of a series of tensile strength tests and pullout tests. The unconfined tensile strength of biaxial geogrid and triaxial geogrid in different loading directions relative to the orientation of ribs was investigated by the tensile strength test. Then, more than 8 pullout tests had been conducted at constant displacement rate on the triaxial geogrid specimens embedded in the compacted sand by varying the applied normal stresses. The pullout response, including pullout resistance and displacements monitored along the geogrid length, was analyzed based on the experimental data. Special attention was also paid to the interface behavior.

\section{Experimental Program}

2.1. Tensile Strength Tests. The unconfined tensile strength of biaxial/triaxial geogrids in different loading directions relative to the orientation of ribs was investigated by the tensile strength test. In this study, the biaxial geogrid (SS20) and triaxial geogrid (TX160) were selected for comparison. Since the test speed has obvious influence on the tensile response of the geogrid [12], six specimens of $200 \mathrm{~mm}$ long and $200 \mathrm{~mm}$ wide in each direction for both the SS20 and TX160 were tested at the same displacement rate as the pullout test which was $1 \mathrm{~mm} / \mathrm{min}$.

Figure 2 shows the comparison of ultimate tensile strength in different loading directions. Good consistency is observed for the ultimate tensile strength both in the $0^{\circ}$ and $90^{\circ}$ loading directions. However, much higher ultimate tensile strengths of the TX160 are recorded in other loading directions, especially in the $45^{\circ}$ loading direction, in the direction of which the SS20 is weakest. This was also demonstrated by the numerical analysis performed by Dong et al. [5]. It is clear that the TX160 has been shown to provide nearly uniform tensile strength in all loading directions as compared with the SS20. Therefore, the TX160 is more effective and efficient to carry uniaxial tension form different directions than SS20. Apart from this, the triaxial geogrid has also been shown to provide improved performance involving bearing capacity and dynamic stress relief of geogrid-reinforced platform or subgrade, as compared with the biaxial geogrid $[15,16]$.

2.2. Pullout Device. Figure 3 shows a view of the pullout device used in this investigation. The pullout device was composed of test box, a normal stress application system, a pullout load actuator device, a clamping system, and all the supporting load cells and displacement transducers. The dimensions of both the upper and below test box were $600 \mathrm{~mm}$ long, $300 \mathrm{~mm}$ wide, and $150 \mathrm{~mm}$ high. A steel loading frame connected with two steel rods to the hydraulic actuator was used to apply the normal stress. The pullout load was also applied using the hydraulic actuator which allowed for a pullout test speed varying from 0.02 to $3 \mathrm{~mm} /$ min. For the testing program conducted in this study, a constant displacement rate of $1 \mathrm{~mm} / \mathrm{min}$ was adopted, as was also the case in some literature stuides [10]. The loading system was capable to apply a normal load and a tensile force both up to $100 \mathrm{kN}$ to a geosynthetic specimen embedded in compacted soil. Load cells and displacement transducers allowed for the measurements of normal stress $\left(\sigma_{\mathrm{n}}\right)$ applied on the sample, normal displacement of the loading plate, pullout force $(P)$, and pullout displacement throughout the test.

2.3. Materials. Figure 4 presents part of the properties of experimental materials used in this study. Standard sand suitable for sand filling method was used in the pullout test for the preparation of samples, whose mainly properties are summarized in Table 1. The particle size distribution curve of the standard sand is shown in Figure 4(a). This was a relatively uniform sand $\left(C_{\mathrm{u}}=1.92\right.$ and $\left.C_{\mathrm{c}}=1.4\right)$ with particle diameters varying between 0.1 and $0.8 \mathrm{~mm}$. A maximum dry density of $1.646 \mathrm{~g} / \mathrm{cm}^{3}$ was obtained through standard Proctor compaction tests with a minimum void ratio of 0.994. The triaxial geogrid made of polypropylene was used in this study. It is well known that the test speed has a 


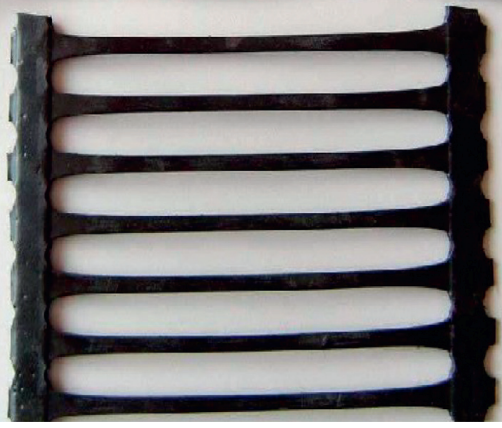

(a)

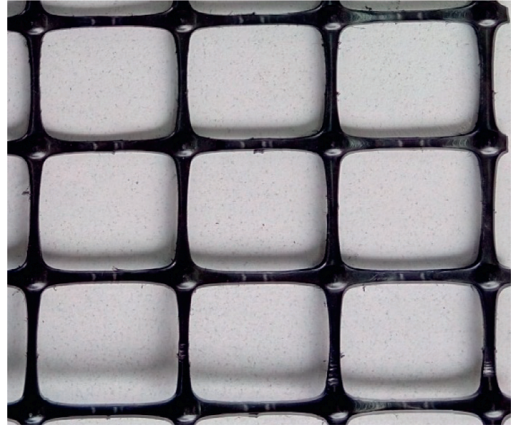

(b)

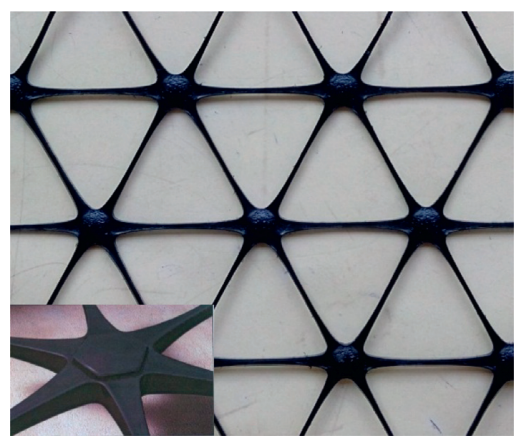

(c)

FIgURE 1: Three kinds of geogrids. (a) Uniaxial geogrid. (b) Biaxial geogrid. (c) Triaxial geogrid.

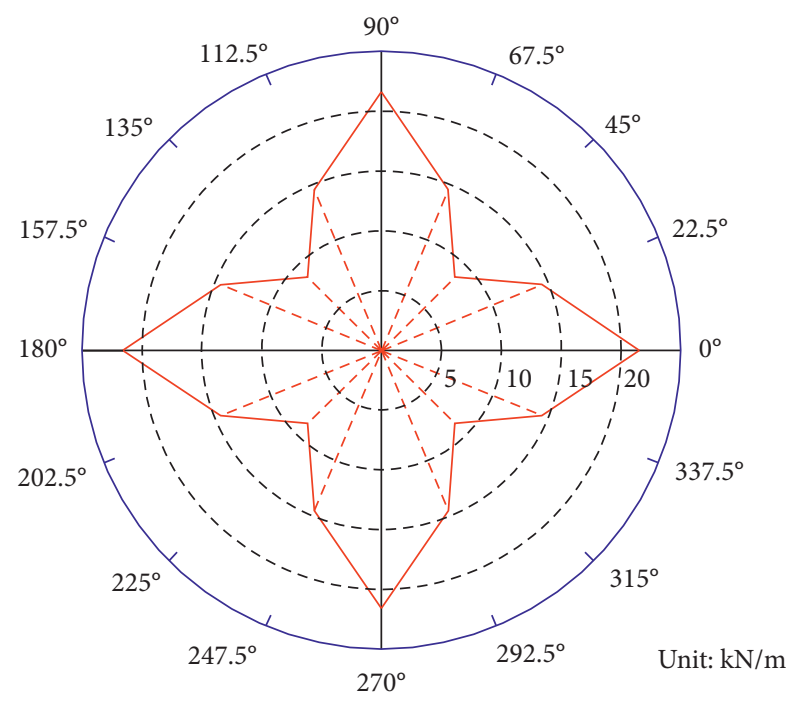

(a)

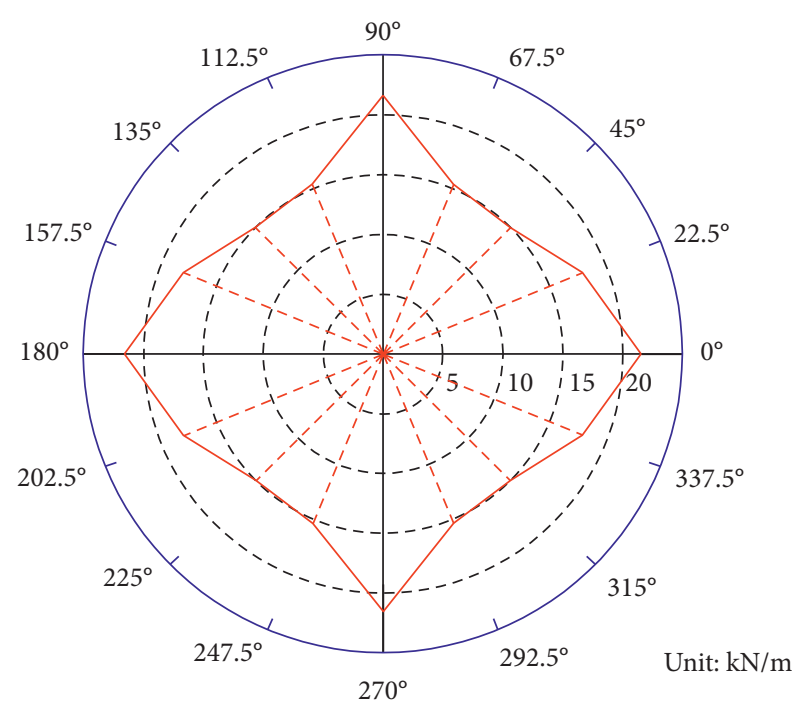

(b)

Figure 2: Comparison of ultimate tensile strength in different loading directions. (a) Biaxial geogrid (SS20). (b) Triaxial geogrid (TX160).

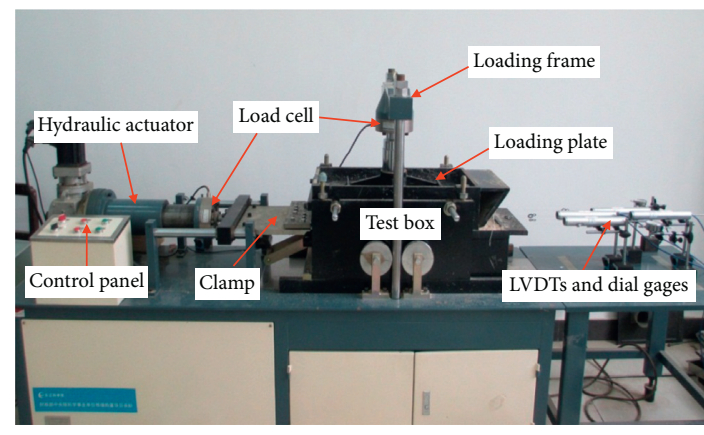

FIgURE 3: View of pullout test device used in this study.

significant influence on the tensile response of the geogrid. Therefore, six triaxial geogrid specimens which were $160 \mathrm{~mm}$ long and $240 \mathrm{~mm}$ wide had been tested employing unconfined tensile tests performed at the same displacement rate as the pullout tests which was $1 \mathrm{~mm} / \mathrm{min}$. Three kinds of tensile directions of the triaxial geogrid, including $0^{\circ}, 60^{\circ}$, and $90^{\circ}$, are defined, as illustrated in Figure 4(b). In this study, both of the tensile test and pullout test were only performed in $0^{\circ}$ direction. The physical and mechanical properties of triaxial geogrid are listed in Table 2.

2.4. Test Procedure. Pullout tests were conducted using $195 \mathrm{~mm} \times 225 \mathrm{~mm}$ geogrid specimens as per Test Methods of Geosynthetics for Highway Engineering in China. Normal stresses of 10,20,30, and $40 \mathrm{kPa}$ were applied throughout the pullout tests for evaluating the effects of confinement. The sand filled in the test box both below and upper the geogrid were compacted to the target degree of compaction in layers using a manual hammer. The initial relative density and void ratio of the soil samples after preparation were equal to $90 \%$ and 0.648 , respectively. A constant stress rate of $0.5 \mathrm{kPa} / \mathrm{s}$ was adopted to apply the normal stress until the target stress level was reached. Then, the normal stress should be maintained at least for three minutes before the pretension force of $0.2 \mathrm{kN}$ was applied aiming at achieving the close contact of each part. In this study, all the tests and measurements had been performed until tensile failure of the geogrid or a total pullout displacement of $20 \mathrm{~mm}$ was achieved. Table 3 summarizes the scope of the pullout testing 


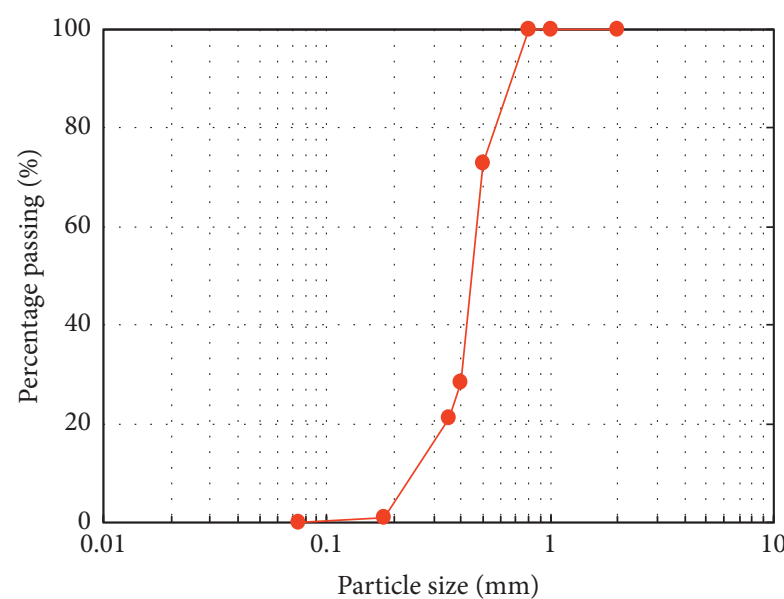

(a)

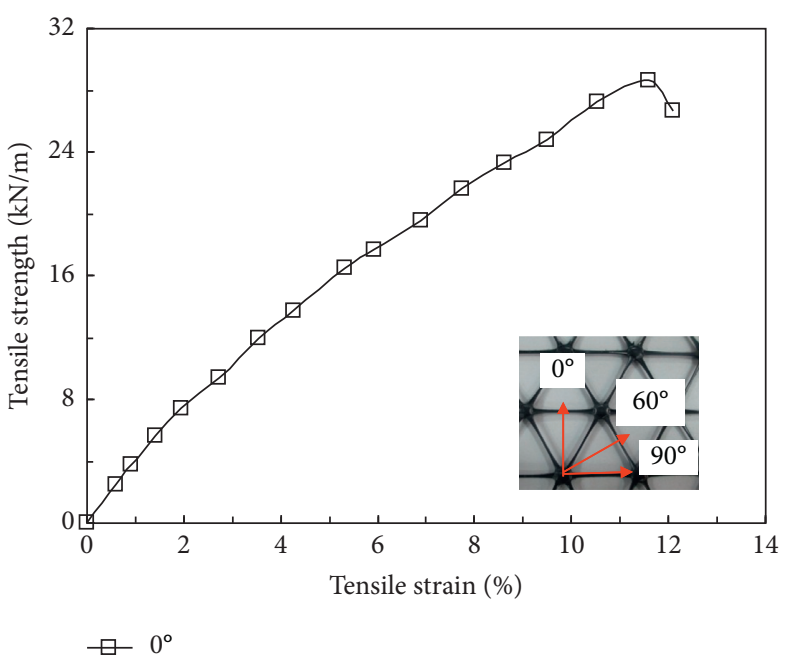

(b)

Figure 4: Experimental material properties. (a) Particle size distribution curve of standard sand. (b) Tensile strength of the triaxial geogrid in $0^{\circ}$ direction.

TABle 1: Physical properties of standard sand.

\begin{tabular}{lcccccccc}
\hline$d_{60}(\mathrm{~mm})$ & $d_{30}(\mathrm{~mm})$ & $d_{10}(\mathrm{~mm})$ & $C_{\mathrm{u}}$ & $C_{\mathrm{c}}$ & $e_{\max }$ & $e_{\min }$ & $\rho_{\max }\left(\mathrm{g} / \mathrm{cm}^{3}\right)$ & $\rho_{\min }\left(\mathrm{g} / \mathrm{cm}^{3}\right)$ \\
\hline 0.48 & 0.41 & 0.25 & 1.92 & 1.40 & 0.610 & 0.994 & 1.646 & 1.329 \\
\hline
\end{tabular}

Note: $d_{60}=$ limiting size; $d_{30}=$ median size; $d_{10}=$ effective size; $C_{\mathrm{u}}=$ coefficient of uniformity; $C_{\mathrm{c}}=$ coefficient of curvature; $e_{\max }=$ maximum void ratio; $e_{\min }=$ minimum void ratio; $\rho_{\max }=$ maximum dry density; $\rho_{\min }=$ minimum dry density.

TABLE 2: Physical and mechanical properties of the triaxial geogrid.

\begin{tabular}{|c|c|c|c|c|c|c|}
\hline \multirow[t]{2}{*}{ Tensile direction } & \multirow[t]{2}{*}{ Aperture size (mm) } & \multirow[t]{2}{*}{$\begin{array}{c}\text { Specimen size } \\
(\text { length } \times \text { width }) / \mathrm{mm}\end{array}$} & \multirow[t]{2}{*}{ Ultimate tensile strength $(\mathrm{kN} / \mathrm{m})$} & \multirow[t]{2}{*}{ Ultimate elongation (\%) } & \multicolumn{2}{|c|}{$\begin{array}{l}\text { Tensile } \\
\text { modulus } \\
(\mathrm{kN} / \mathrm{m})\end{array}$} \\
\hline & & & & & $2 \%$ & $5 \%$ \\
\hline $0^{\circ}$ & 45 & $160 \times 240$ & 28.7 & 11.6 & 232.0 & 192.0 \\
\hline
\end{tabular}

TABLE 3: Testing program.

\begin{tabular}{lccccc}
\hline $\begin{array}{l}\text { Pullout } \\
\text { direction }\end{array}$ & $\begin{array}{c}\text { Loading speed } \\
(\mathrm{mm} / \mathrm{min})\end{array}$ & $\begin{array}{c}\text { Normal stress } \\
(\mathrm{kPa})\end{array}$ & $\begin{array}{c}\text { Degree of } \\
\text { compaction }(\%)\end{array}$ & $\begin{array}{c}\text { Specimen size } \\
(\text { length } \times \text { width }) / \mathrm{mm}\end{array}$ & $\begin{array}{c}\text { Longitudinal spacing of } \\
\text { measuring sections }(\mathrm{mm})\end{array}$ \\
\hline $0^{\circ}$ & 1 & $10 / 20 / 30 / 40$ & 90 & $195 \times 225$ & $78 / 39$ \\
\hline
\end{tabular}

program. In order to ensure the repeatability and reliability of the pullout tests results, the pullout tests under each stress level were performed at least two times.

As the deformation or strain of the geogrid specimens embedded in the compacted sand is not easy to be measured directly, the indirect measuring method was put forward. In this study, four linear variable displacement transformers (LVDTs) connected to points ${ }^{\#} 1$, ${ }^{\#} 2-1$, ${ }^{*} 2-2$, and ${ }^{\#} 3-1$ and three dial gages connected to points ${ }^{\#} 3-2,{ }^{*} 3-3$, and ${ }^{*} 4$ using inextensible and smooth steel wires were adopted to monitor and record the internal displacements along the geogrid specimen. Specifically, displacements of the geogrid specimen were monitored at four sections, which were $39,107,185$, and $224 \mathrm{~mm}$ from the clamp in turn, as shown in Figure 5(a).
Afterwards, the elongation of the geogrid specimen between two sections could be calculated. All the measurements were automatically collected and digitally recorded on a portable computer at defined constant time intervals.

\section{Test Results and Analysis}

3.1. Geometry Deformation Characteristic. Figure 5(b) shows the geometry deformation after pullout test performed on the geogrid specimens under the normal stress of $10 \mathrm{kPa}$ and $30 \mathrm{kPa}$, respectively. An increasing normal stress had led to the significantly increased geometry deformation, which were mainly characterized by rib bending and nodal distortion. Analysis suggested that an inward squeeze 


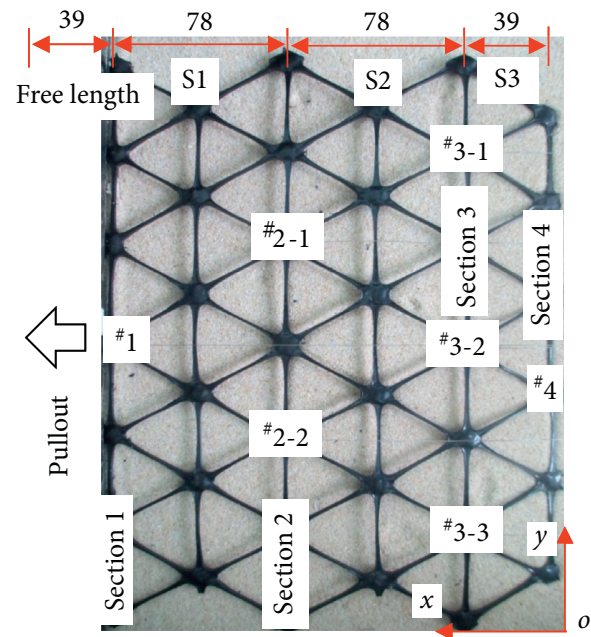

(a)
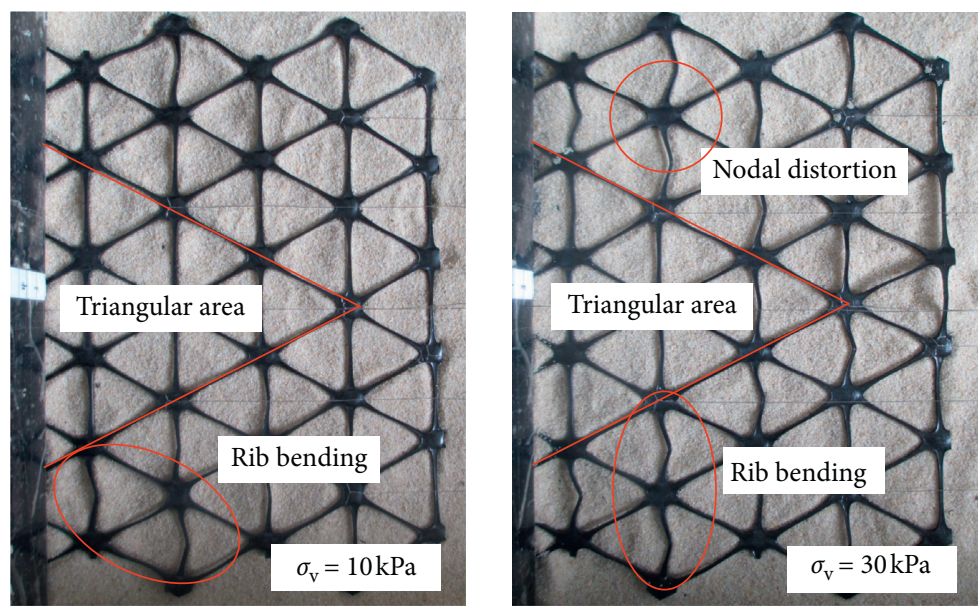

(b)

Figure 5: Layout of measuring positions and geometry deformation after pullout test. (a) Layout of measuring points and sections (unit: $\mathrm{mm})$, (b) Geometry deformation after pullout test.

perpendicular to the pullout direction of the geogrid specimens was very obvious during the pullout test, thus leading to rib bending and nodal distortion along the two sides of the geogrid specimens. A triangular area with relative slight deformation is also marked in Figure 5(b).

3.2. Pullout Resistance. The pullout resistance is usually evaluated in terms of pullout force-displacement curves, from which the peak pullout resistance $P_{\mathrm{R}}$, corresponding to the maximum value of pullout force, and the residual pullout resistance $P_{\mathrm{RR}}$, corresponding to the ultimate value of pullout force, are easy to be obtained. Figure 6(a) illustrates the pullout force-displacement curves measured at the clamp under different normal stresses. Pullout force was seen increasing with increase in pullout displacement at the initial phase, followed by a strain-softening behavior with a progressive decrease of pullout force after the peak value. In these tests, the decrease of pullout force was also possible attributed to the decrement of shear area due to part of the specimen, previously embedded into the soil, leaving the soil as the clamp was not inserted into the soil. It was evident that the pullout behavior was strongly influenced by the applied normal stress. The increase of normal stress had led to increasing pullout force, increased initial stiffness, and increased strain-softening of the pullout force after the peak value. A larger pullout displacement corresponding to the peak pullout force was expected as the increase of normal stress. It should be noted that the pullout displacement at which the peak pullout force was obtained increased approximately linearly with the normal stress, as shown in Figure 6(b).

3.3. Displacement Behavior. For the extensible geogrid, the interface friction between the geogrid and the soil usually developed in a progressive mode, leading to a nonuniform distribution pattern along the geogrid length. In this condition, the pullout displacement was composed of the geogrid tensile deformation and the translation motion at the free end of the specimen. Analysis of the displacement along geogrid length could provide a valuable insight into the developing mechanism of interface friction.

Figure 7 shows the displacement of measuring sections along the geogrid length versus pullout displacement of the clamp. The results show that the displacements of measuring sections were highly dependent on the free part of the specimen between the clamp and the soil boundary (section 1) and the applied normal stress. As the increase of normal stress, the displacement of section 1 fell behind that of the clamp significantly due to the influence of free part of the specimen. The difference between two measuring sections reflected the extension of the geogrid between these two sections. The maximum displacement occurred at section 1 and decreased towards the back of the geogrid following a nonlinear trend which indicated the effect of geogrid extensibility. An increasing difference of the displacement between sections 1 and 2 was significantly observed as the increase of normal stress. The difference of displacement between sections 3 and 4 was not obvious. Thus, the interface friction of triaxial geogrid developed in a progressive mode.

3.4. Interface Behavior and Parameters. Figure 8 shows the applied pullout force as a function of internal section displacements along the geogrid length during the pullout tests. The pattern of the pullout force versus the displacements, measured at different sections shown that an approximate rigid-plastic behavior was observed for sections 3 and 4 which were close to the free end of the specimen under each normal stress level, while an approximate elasto-plastic-softening characteristic was observed for sections 1 and 2 that were close to the clamp as the increase of normal stress. This was mainly attributed to the effect of geogrid extensibility. 

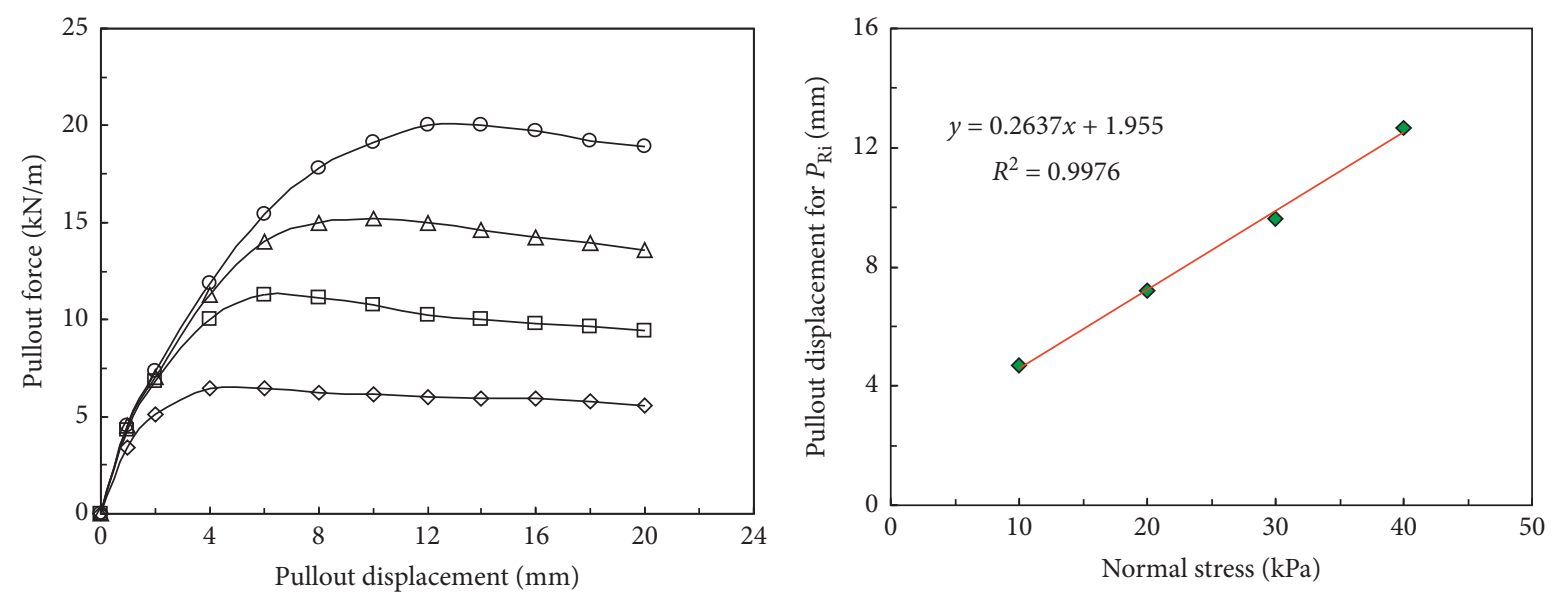

$\begin{array}{ll}\diamond 10 \mathrm{kPa} & \triangle 30 \mathrm{kPa} \\ \square 20 \mathrm{kPa} & -40 \mathrm{kPa}\end{array}$

(a)

(b)

FIgURE 6: Pullout force versus pullout displacement.
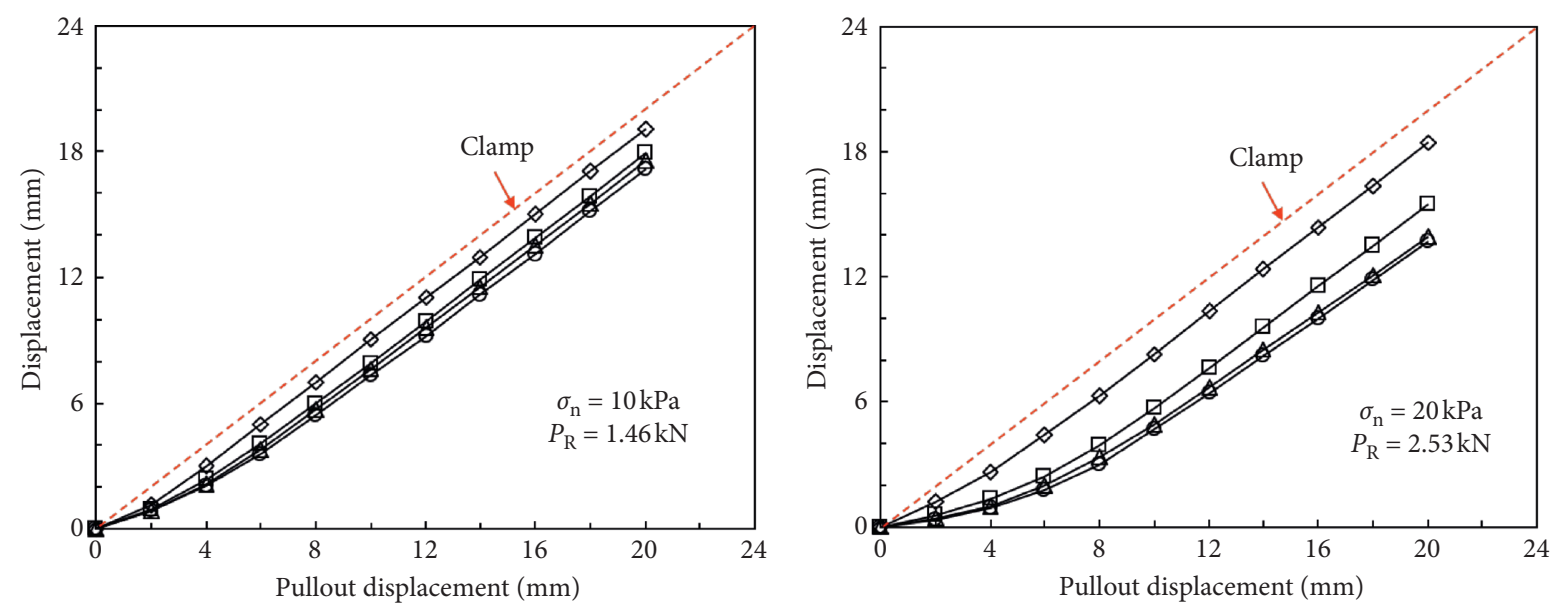

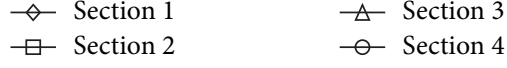

(a)

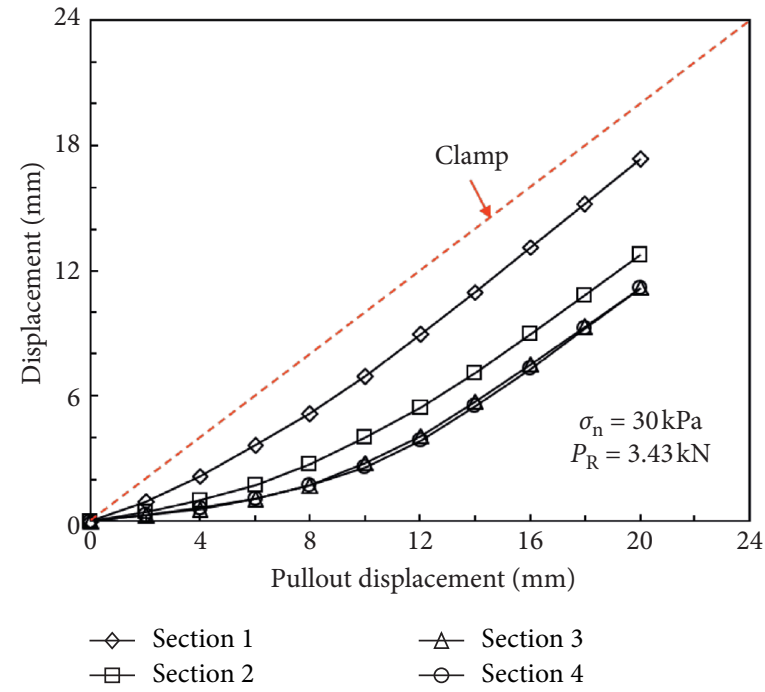

(c)

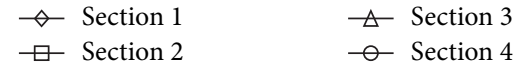

(b)

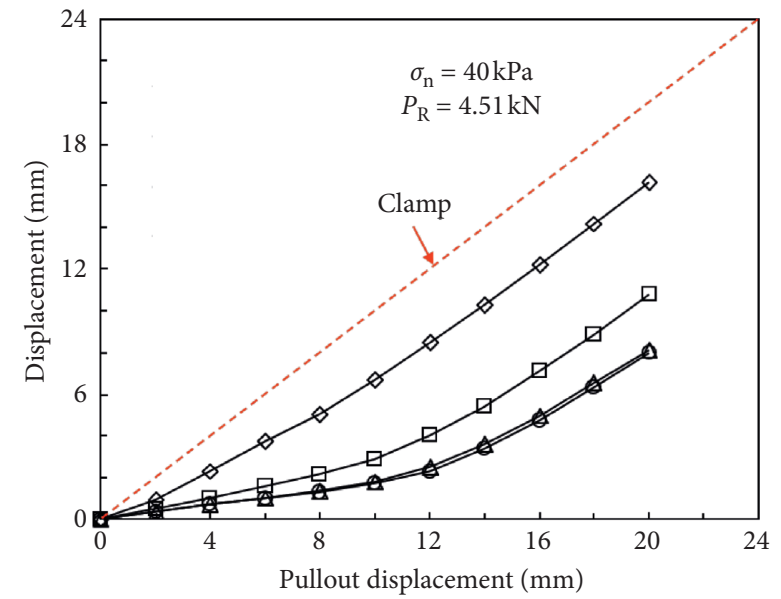

$\diamond$ Section 1

$\triangle$ Section 3

$\square$ Section 2

(d)

Figure 7: Displacements of measuring sections versus pullout displacement. 

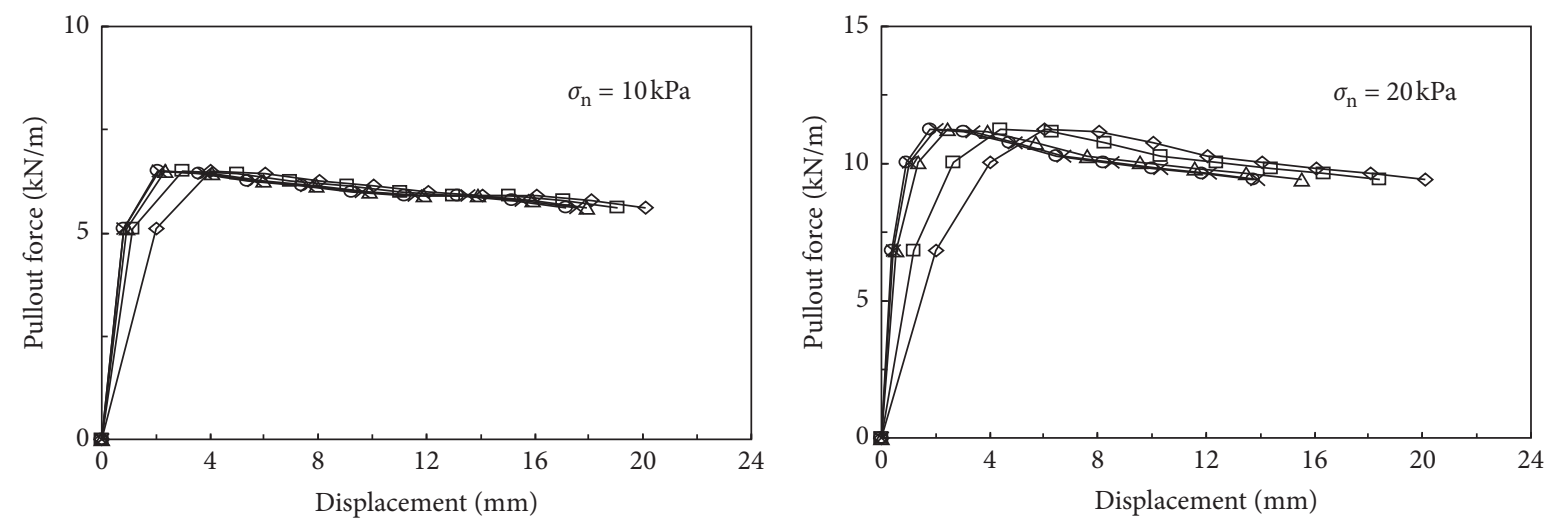

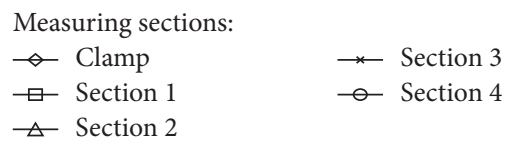

(a)

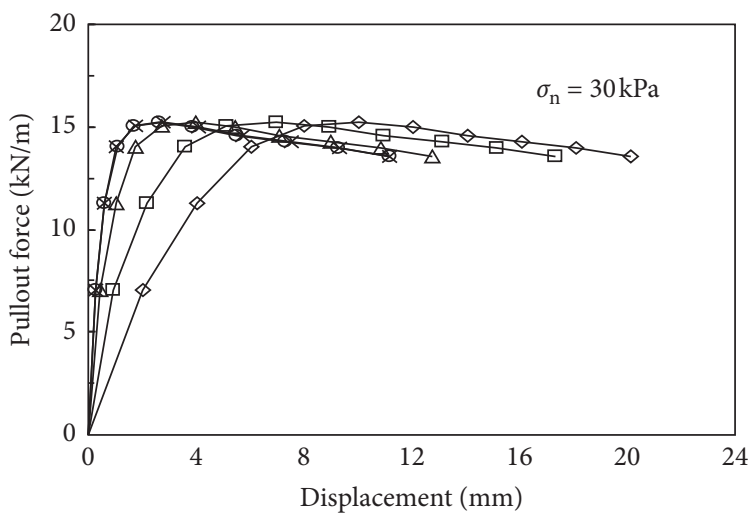

Measuring sections:

$\begin{array}{ll}\hookrightarrow \text { Clamp } & \rightarrow \text { Section } 3 \\ \square \text { Section 1 } & - \text { Section } 4 \\ \triangle \text { Section 2 } & \end{array}$

(c)

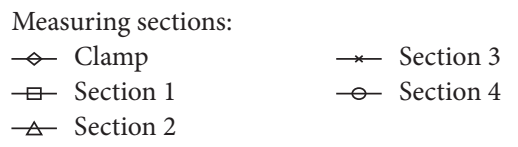

(b)

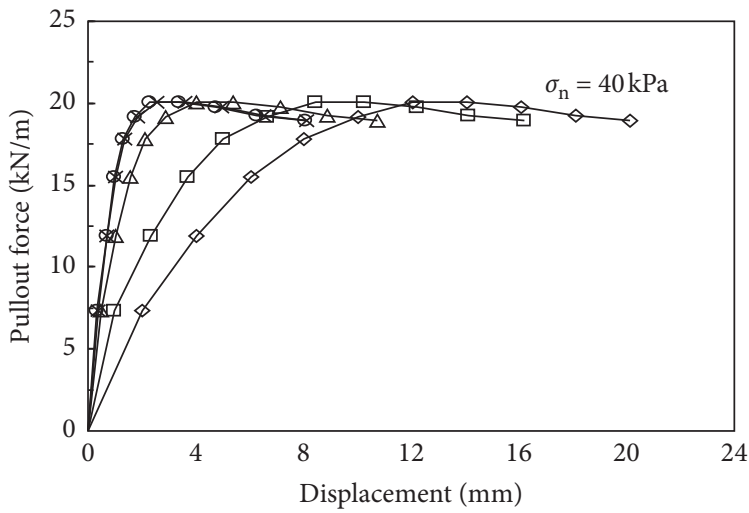

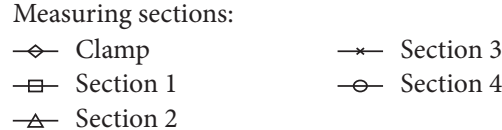

(d)

FIGURE 8: Relationship between pullout force and displacements of measuring sections.

The interface behavior between geogrid and soil was commonly described and evaluated in terms of interface strength parameters $(c, \varphi)$ and interface apparent coefficient of friction $\left(\mu_{\mathrm{P}}, \mu_{\mathrm{R}}\right)$. If the interface friction distribution was assumed to be uniform, the peak interface shear stress and residual interface shear stress were found to be directly proportional to normal stress, with the correlation coefficient up to 0.9965 and 0.9994, as shown in Figure 9(a), in spite of the complex stress transfer mechanisms that took place during pullout test. The residual interface cohesion was $1.78 \mathrm{kPa}$, smaller than the peak interface cohesion of $6.1 \mathrm{kPa}$, while the residual angle of friction, which was $49.02^{\circ}$, was larger than the peak angle of friction of $47.78^{\circ}$. This evolution of interface parameters is attributed to the geometry deformation of the geogrid specimens, especially the out-ofplane bending. Figure 9(b) shows both the peak and residual apparent coefficient of friction as function of the normal stress. The peak and residual apparent coefficient of friction can be evaluated by means of the following expressions:

$$
\begin{aligned}
& \mu_{\mathrm{P}}=\frac{\tau_{\mathrm{P}}}{\sigma_{\mathrm{n}}}, \\
& \mu_{\mathrm{R}}=\frac{\tau_{\mathrm{R}}}{\sigma_{\mathrm{n}}} .
\end{aligned}
$$

where $\tau_{\mathrm{P}}$ is the peak interface shear stress and $\tau_{\mathrm{R}}$ is the residual interface shear stress.

Both of the residual apparent coefficient of friction, $\mu_{\mathrm{R}}$, and the peak apparent coefficient of friction, $\mu_{\mathrm{P}}$, decreased with the increase in normal stress, as shown in Figure 9(b). This could be mainly attributed to a greater dilative response of the dense sand under low stresses [2]. $\mu_{\mathrm{R}}$ was also expected to be smaller than $\mu_{\mathrm{P}}$ due to the effect of strain-softening, as shown in Figure 6(a). 


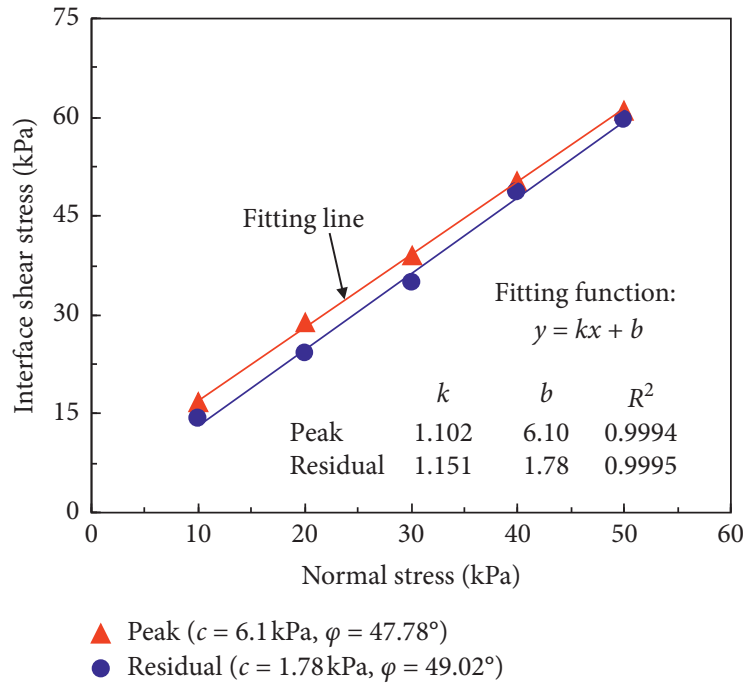

(a)

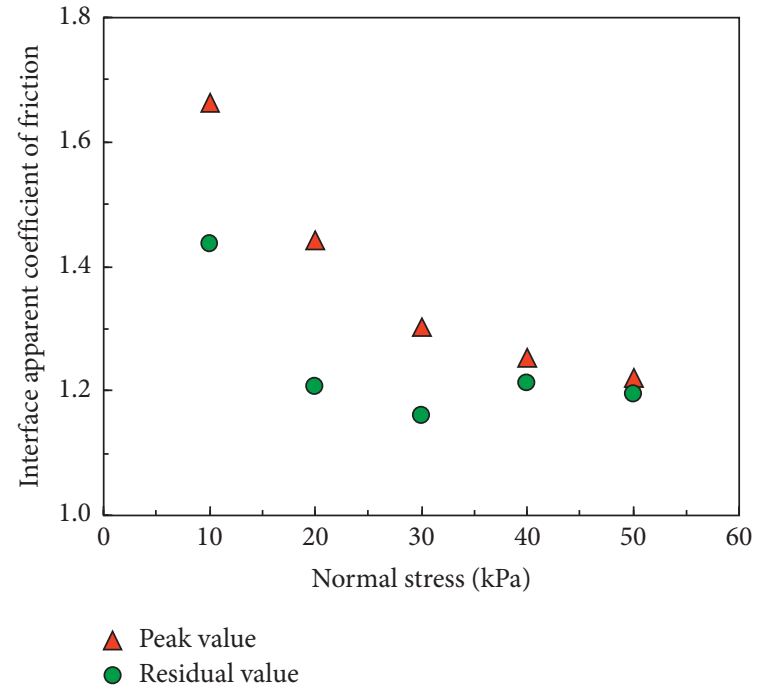

(b)

FiguRE 9: Interface parameters. (a) Interface strength. (b) Apparent coefficient of friction.

\section{Conclusions}

A series of unconfined tensile strength tests and pullout tests have been conducted to evaluate the mechanical and interface behavior of triaxial geogrid used for GRS structures. By using the inextensible and smooth steel wires, these laboratory experiments has provide an effective method to investigate the deformation and complex interlocking between the triaxial geogrid and compacted sand under different normal stresses. The main conclusions obtained are summarized as follows:

(1) The triaxial geogrid has been shown to provide nearly uniform tensile strength in all loading directions as compared with the biaxial geogrid. This advantage can contribute to the usage of triaxial geogrid in the GRS structures of which the unanticipated failure is possible in random directions.

(2) The geometry deformation of the geogrid specimen after pullout test was mainly characterized by rib bending and nodal distortion. An inward squeeze perpendicular to the pullout direction of the geogrid specimen was obviously observed during the pullout test. The pullout resistance was strongly influenced by the applied normal stress. In order to obtain more accurate test results, a sleeve inserting into the soil was recommended to avoid the shear area decrement of the geogrid specimen during the pullout tests.

(3) The interface friction of triaxial geogrid developed in a progressive mode and an elasto-plastic-softening characteristic for interface behavior was detected due to the extensibility of geogrid. Although the residual interface cohesion was smaller than the peak interface cohesion, the residual angle of friction was larger than the peak angle of friction. This evolution is beneficial to the stability or mitigation of interface displacement of GRS structures, especially in the condition of the occurrence of large deformation occurred.

\section{Data Availability}

The data used to support the findings of this study are included within the article.

\section{Conflicts of Interest}

The authors declare that there are no conflicts of interest regarding the publication of this paper.

\section{Acknowledgments}

The authors are thankful for the financial support received from the National Key R\&D Program of China (grant number: 2018YFB1600100) and the National Natural Science Foundation of China (NSFC) (grant number: 51608316).

\section{References}

[1] S. H. C. Teixeira, B. S. Bueno, and J. G. Zornberg, "Pullout resistance of individual longitudinal and transverse geogrid ribs," Journal of Geotechnical and Geoenvironmental Engineering, vol. 133, no. 1, pp. 37-50, 2007.

[2] E. M. Palmeira, "Soil-geosynthetic interaction: modelling and analysis," Geotextiles and Geomembranes, vol. 27, no. 5, pp. 368-390, 2009.

[3] E. M. Palmeira, "Bearing force mobilisation in pull-out tests on geogrids," Geotextiles and Geomembranes, vol. 22, no. 6, pp. 481-509, 2004.

[4] Q. Yu, J. Han, S. K. Pokharel, and R. L. Parsons, "Performance of triangular aperture geogrid-reinforced base courses over weak subgrade under cyclic loading," Journal of Materials in Civil Engineering, vol. 25, no. 8, pp. 1013-1021, 2013.

[5] Y.-L. Dong, J. Han, and X.-H. Bai, "Numerical analysis of tensile behavior of geogrids with rectangular and triangular 
apertures," Geotextiles and Geomembranes, vol. 29, no. 2, pp. 83-91, 2011.

[6] Q. Yu, J. Han, S. K. Pokharel, and R. L. Parsons, "Stress analysis on triangular aperture geogrid-reinforced bases over weak subgrade under cyclic loading-an experimental study," in Proceedings of the 10th International Conference on LowVolume Roads, pp. 83-91, Transportation Research Board, Washington, DC, USA, 2011.

[7] C. Chen, G. R. Mcdowell, and N. H. Thom, "Discrete element modelling of cyclic loads of geogrid-reinforced ballast under confined and unconfined conditions," Geotextiles and Geomembranes, vol. 35, pp. 76-86, 2012.

[8] J. J. Zheng, W. Z. Cao, Y. J. Zhou, and J. G. Jiang, "Pull-out test study of interface behavior between triaxial geogrid and soil," Rock and Soil Mechanics, vol. 38, no. 2, pp. 317-324, 2017, in Chinese.

[9] W. Z. Cao, J. J. Zheng, and Y. J. Zhou, "Comparative experimental investigation of geogrid-soil interface behavior of biaxial and triaxial geogrid," Journal of Hunan University (Natural Sciences), vol. 46, no. 1, pp. 109-116, 2019, in Chinese.

[10] M. Sugimoto and A. M. N. Alagiyawanna, "Pullout behavior of geogrid by test and numerical analysis," Journal of Geotechnical and Geoenvironmental Engineering, vol. 129, no. 4, pp. 361-371, 2003.

[11] N. Moraci and P. Recalcati, "Factors affecting the pullout behaviour of extruded geogrids embedded in a compacted granular soil," Geotextiles and Geomembranes, vol. 24, no. 4, pp. 220-242, 2006.

[12] N. Moraci and D. Gioffrè, "A simple method to evaluate the pullout resistance of extruded geogrids embedded in a compacted granular soil," Geotextiles and Geomembranes, vol. 24, no. 2, pp. 116-128, 2006.

[13] M. S. Khedkar and J. N. Mandal, "Pullout behaviour of cellular reinforcements," Geotextiles and Geomembranes, vol. 27, no. 4 , pp. 262-271, 2009.

[14] M. R. Abdi and M. A. Arjomand, "Pullout tests conducted on clay reinforced with geogrid encapsulated in thin layers of sand," Geotextiles and Geomembranes, vol. 29, no. 6, pp. 588-595, 2011.

[15] Y. L. Dong, J. Han, and X. H. Bai, "Bearing capacities of geogrid-reinforced sand bases under static loading," in Proceedings of the 2010 GeoShanghai International Conference, Ground Improvement and Geosynthetics, pp. 275-281, Geotechnical Special Publication No. 207, Reston, VA, USA, 2010.

[16] D. J. White, P. K. R. Vennapusa, H. H. Gieselman, S. C. Douglas, J. Zhang, and M. H. Wayne, "In-ground dynamic stress measurements for geosynthetic reinforced subgrade/subbase," in Proceedings of GeoFrontiers 2011: Advances in Geotechnical Engineering, pp. 4663-4672, Geotechnical Special Publication No. 211, Reston, VA, USA, 2011. 